\title{
CARACTERIZAÇÃO FÍSICO-QUÍMICA DA PALHA DE MILHO OBTIDA DURANTE A ETAPA DE COLHEITA
}

\author{
L. R. BOHN ${ }^{1}$, V. P. CASARA ${ }^{1}$, A. P. DRESCH ${ }^{1}$ e G. M. MIBIELLI ${ }^{1}$, J. P. BENDER ${ }^{1}$ \\ ${ }^{1}$ Universidade Federal da Fronteira Sul, UFFS - Campus Chapecó \\ E-mail para contato: leeticiabohn@gmail.com
}

\begin{abstract}
RESUMO - O Brasil é o segundo maior produtor de álcool combustível do mundo. O etanol atualmente produzido em nosso país é proveniente da fermentação do caldo de cana-de-açúcar e do melaço, substratos ricos em sacarose. A produção brasileira, no entanto, embora já bastante expressiva, pode vir a ter um aumento substancial quando a obtenção desse combustível for viabilizada também a partir de biomassa lignocelulósica. Nesse contexto, a biomassa de milho aparece como destaque no cenário nacional e estadual. Em 2015, o estado de Santa Catarina produziu, em seus 465,4 mil hectares de área plantada, aproximadamente 2,5 milhões de toneladas de palha de milho. Há ainda, porém, grandes desafios a serem enfrentados para viabilizar essa forma de produção de etanol, que pressupõem a otimização das etapas de pré-tratamento da biomassa, hidrólise dos polissacarídeos e fermentação dos hidrolisados. Desse modo, a viabilidade e o desenvolvimento de tecnologias viáveis para a produção de bioetanol, a partir da palha de milho, perpassam, fundamentalmente, pela caracterização química da matéria-prima. Assim, neste trabalho realizou-se a caracterização química da palha de milho, quanto à umidade, cinzas e extrativos. Os resultados demonstraram que a palha apresenta um baixo conteúdo de matéria inorgânica e lignina insolúvel e um alto conteúdo de extrativos.
\end{abstract}

\section{INTRODUÇÃO}

O Brasil, juntamente com os Estados Unidos, é um dos maiores produtores mundiais de etanol, sendo produzido, no Brasil, a partir de matéria-prima sacarínea, caldo de cana, em um processo que se caracteriza pelo seu baixo custo. Já nos Estados Unidos, a produção é provinda do cultivo de milho (grão de milho), sendo necessária a inclusão de uma etapa de hidrólise do material amiláceo, resultando em um custo de produção mais elevado. Em ambos os casos, um aumento na produção, visando suprir a crescente demanda mundial pelo etanol, obrigaria a ampliação das áreas de cultivo, a qual compete diretamente com a indústria alimentícia. Além disso, a utilização de alimentos para a produção de biocombustíveis é um grande dilema, pois pode contribuir para o desequilíbrio entre a oferta e a demanda de alimentos no mundo, além de sustentar os altos preços desses produtos.

Nesse contexto faz-se necessário o desenvolvimento de rotas de produção a partir de diferentes matérias-primas, as pesquisas atuais sinalizam a necessidade do desenvolvimento de processos, de base biotecnológica, que permitam à utilização dos resíduos já existentes para a produção de etanol. Dentre os possíveis resíduos, os materiais lignocelulósicos, gerados da própria atividade agrícola e agro-industrial, possuem o potencial suficiente para se 
tornarem matéria-prima para a produção de etanol. Uma fonte de biomassa lignocelulósica que apresenta destaque no cenário Brasileiro e até mesmo em países como os Estados Unidos e China é a biomassa proveniente da colheita do milho. No Brasil, são produzidos anualmente cerca de 84 milhões de toneladas de grãos, em uma área de aproximadamente 15 milhões de hectares (CONAB, 2016), referentes a duas safras: normal e safrinha. Segundo o Instituto Brasileiro de Geografia e Estatística (IBGE), aproximadamente 4\% da produção total de milho produzido no Brasil é proveniente do estado de Santa Catarina, com uma área plantada de 465,4 mil hectares e com uma expectativa de produção de quatro milhões de toneladas.

Em função das questões expostas, este estudo reporta a caracterização química da palha de milho, a qual se apresenta como a etapa inicial para o entendimento da possibilidade de utilização desta biomassa para a produção de etanol de segunda geração.

\section{Metodologia}

\subsection{Obtenção e preparo da biomassa palha de milho}

A biomassa, palha de milho, utilizada nos experimentos foi obtida nas áreas experimentais da Universidade Federal da Fronteira Sul - Campus Chapecó.

Após a colheita do milho, a biomassa restante no campo foi coletada e armazenada em câmaras de refrigeração. O resfriamento torna-se necessário tendo em vista o processo de degradação que a biomassa poderia sofrer em temperatura ambiente, até o inicio das análises. Primeiramente a biomassa foi separada de materiais indesejáveis, como terra, restos de vegetação, entre outros elementos que possam interferir nos resultados, restando apenas a biomassa lignocelulósica de milho, a qual foi separada em três frações: palha, caule e folha. Sendo a palha o material que envolve a espiga do milho, o caule é o material que fornece sustentação a planta e a folha é o material preso ao caule.

Realizada a separação, o material passou pela etapa de pré-secagem em estufa e redução de tamanho em moinho de facas, até a obtenção de partículas com tamanhos inferiores a 0,5 $\mathrm{mm}$, selecionadas através de uma peneira acoplada ao próprio equipamento. Em subsequência, realizaram-se as análises de umidade final, granulometria, teor de cinzas, extrativos e lignina solúvel.

\subsection{Análise granulométrica}

Para a determinação da distribuição do tamanho de partículas na biomassa, utilizou-se como referência o procedimento padrão NREL "Determination of Total Solids in Biomass" (Hames et al. 2005). Peneiras na série Taylor 9, 16, 30, 60 e 100 mesh foram utilizadas para a separação do material. Inicialmente pesaram-se as peneiras, que posteriormente são empilhadas na seguinte ordem, começando na parte inferior: a bandeja inferior, 100, 60, 30, 16 e 9 mesh. Em seguida, foi adicionado aproximadamente $80 \mathrm{~g}$ do material em análise na parte superior da série de peneiras e estas foram presas em um agitador eletromagnético, sendo agitadas durante $15 \mathrm{~min}$. Ao término do período, pesaram-se as peneiras para determinar a massa retida em cada uma delas. 
Cabe salientar que foi utilizada, para a realização das análises de umidade, teor de cinzas, extrativos e lignina solúvel, a biomassa que passou pela peneira de 30 mesh. Ao término do experimento o material foi armazenado, em bolsas hermeticamente fechadas, dentro do freezer, seguindo o mesmo procedimento descrito por Rabelo (2010).

\subsection{Teor de umidade e sólidos totais}

Estufa: A determinação do teor de umidade da biomassa seguiu o procedimento padrão do NREL "Determination of Total Solids in Biomass" (Sluiter et al. 2005). O objetivo desta análise era medir a quantidade de água e outros componentes voláteis à $105^{\circ} \mathrm{C}$ presentes nas amostras. O teor de umidade da biomassa foi calculado pela Equação 1. Enquanto que o índice de sólidos totais da amostra pode ser calculado pela Equação 2.

$$
\% \text { umidade }=\left(1-\left(\left(M \_3-M \_1\right) /\left(M \_2-M \_1\right)\right)\right) \times 100
$$

Onde: $\mathrm{M}_{1}$ é a massa do béquer vazio, em $\mathrm{g} ; \mathrm{M}_{2}$ é a massa do béquer + amostra úmida, em $\mathrm{g}$ e $\mathrm{M}_{3}$ é a massa do béquer + amostra absolutamente seca, em $\mathrm{g}$.

$$
\% \text { sólidos totais }=100-\% \text { umidade }
$$

Infra-vermelho: Para a determinação do teor de umidade por infravermelho utilizou-se o equipamento da marca GEHAKA, modelo IV2500.

\subsection{Teor de cinzas}

Com a finalidade de quantificar o material inorgânico na biomassa, estrutural ou extraível, como parte da composição total, utilizou-se o procedimento padrão NREL "Determination of Total Solids in Biomass" (Sluiter et al. 2005). Para a determinação do teor de cinzas utilizaram-se cadinhos de porcelana de $50 \mathrm{~mL}$, devidamente inumerados e pesados em uma balança analítica. Pesou-se cerca de 1,00 g do material, descontando o teor de umidade, nos cadinhos previamente pesados. Realizou-se a carbonização do mesmo em mufla a $800^{\circ} \mathrm{C}$ por $20 \mathrm{~min}$. Repetiu-se a calcinação por mais $15 \mathrm{~min}$ para se verificar a constância do peso, efetuaram-se as análises em triplicata (Rabelo, 2010). Para o cálculo do teor de cinzas utilizou-se na Equação 3.

$$
\text { \%cinzas=((M_3-M_1)/(M_2-M_1 ) }) \times 100
$$

Onde: $\mathrm{M}_{1}$ é a massa do cadinho vazio, em $\mathrm{g} ; \mathrm{M}_{2}$ é a massa do cadinho vazio + massa da biomassa descontando o teor de umidade, em $\mathrm{g} ; \mathrm{M}_{3}$ é a massa do cadinho com cinzas, em $\mathrm{g}$.

\subsection{Teor de extrativos}

Desempenhou-se os experimentos baseando-se nos procedimentos padrões NREL "Determination of Total Solids in Biomass" (Sluiter et al. 2005) e na norma TAPPI T "Solvent Extractives in Biomass" (TAPPI,1996). Adicionou-se aproximadamente 4,00 g da 
amostra, descontando o teor de umidade, ao cartucho de extração tendo sua massa devidamente anotada. Após a montagem do extrator, o cartucho preenchido pela biomassa foi introduzido no tubo de extração do soxhlet. Logo, adicionou-se $200 \mathrm{~mL}$ de água destilada em cada balão do extrator juntamente com pérolas de vidro. Colocam-se os balões no extrator e ligou-se o aquecimento do mesmo para que o processo de sifonações inicia-se. A extração ocorreu até que o solvente em torno do cartucho se tornou incolor. Posteriormente, repetiu-se o mesmo processo utilizando $150 \mathrm{~mL}$ de álcool etílico. Para o cálculo do teor de extrativos recorre-se a Equação 4.

$$
\% \text { extrativos=((M_1-M_2)/M_1 }) \times 100
$$

Onde: M1 é a massa da biomassa descontando o teor de umidade, em g; M2 é a massa da biomassa livre de extrativos, em $\mathrm{g}$.

\subsection{Teor de lignina insolúvel}

Para a determinação da lignina insolúvel, realizou-se primeiramente uma hidrólise ácida concentrada, onde pesou-se aproximadamente $0,30 \mathrm{~g}$ de cada amostra, descontando o teor de umidade, em tubos de ensaio devidamente etiquetados. Adicionou-se 3,00 mL de ácido sulfúrico a $72 \%(\mathrm{~m} / \mathrm{m})$ em cada tubo. Posteriormente, os tubos foram incubados em banho termostático a $30^{\circ} \mathrm{C}$ por $1 \mathrm{~h}$. Usou-se um bastão de vidro para agitar as amostras a cada 5-10 min, sem remover os tubos do banho. Logo, no processo de hidrólise ácida diluída, depois de decorrido o tempo da hidrólise ácida concentrada, removeu-se os tubos do banho e transferiuse o conteúdo quantitativamente para erlenmeyers de $250 \mathrm{~mL}$, utilizando para isso, $84 \mathrm{~mL}$ de água destilada, sendo a concentração ácida do meio diluída para 4\%. Preparou-se um branco com ácido sulfúrico a 4\%. Para a completa hidrólise dos oligômeros, fecharam-se os erlenmeyers com papel alumínio e elásticos e os colocou em uma autoclave, por $1 \mathrm{~h} \mathrm{a} 121^{\circ} \mathrm{C}$ e 1,1 bar. Após a descompressão da autoclave, os frascos foram retirados e resfriados à temperatura ambiente antes de remover o papel alumínio.

Os hidrolisados ácidos foram filtrados em funil utilizando-se papéis de filtro, em seguida, o papel filtro juntamente com os sólidos retidos foram transferidos para Placas de Petri e encaminhados para estufa a $40^{\circ} \mathrm{C}$ até massa constante (Aproximadamente $40 \mathrm{~min}$ ). Para que não houvesse uma superestimação dos dados de lignina insolúvel, o teor de cinzas, segundo o método já explanado, foi descontado nos cálculos. Como demonstra a Equação 5.

$\%$ lignina insolúvel $1=\left(\left(\mathbf{M} \_2 / \mathrm{M} \_1\right) \times 100\right)-\%$ cinzas

Onde: M1 é a massa da biomassa utilizada na hidrólise descontando o teor de umidade, em g; M2 é a massa da lignina insolúvel seca, em g; \% cinzas: teor de cinzas, determinado segundo a Equação 3.

\section{RESULTADOS E DISCUSSÕES}

\subsection{Granulometria}


Após o processo de secagem, separação inicial e moagem, em moinhos de faca, realizou-se a análise granulométrica da palha de milho, passando-se o material por peneiras da Série Taylor, com malhas de 9, 16, 30, 60 e 100 mesh, equivalentes a uma abertura de malha de 2, 1, 0,6, 0,297 e 0,15mm, respectivamente. O percentual de amostra retida em cada peneira é apresentado na Figura 1.

Figura 1 - Percentual de palha de milho retida em cada peneira

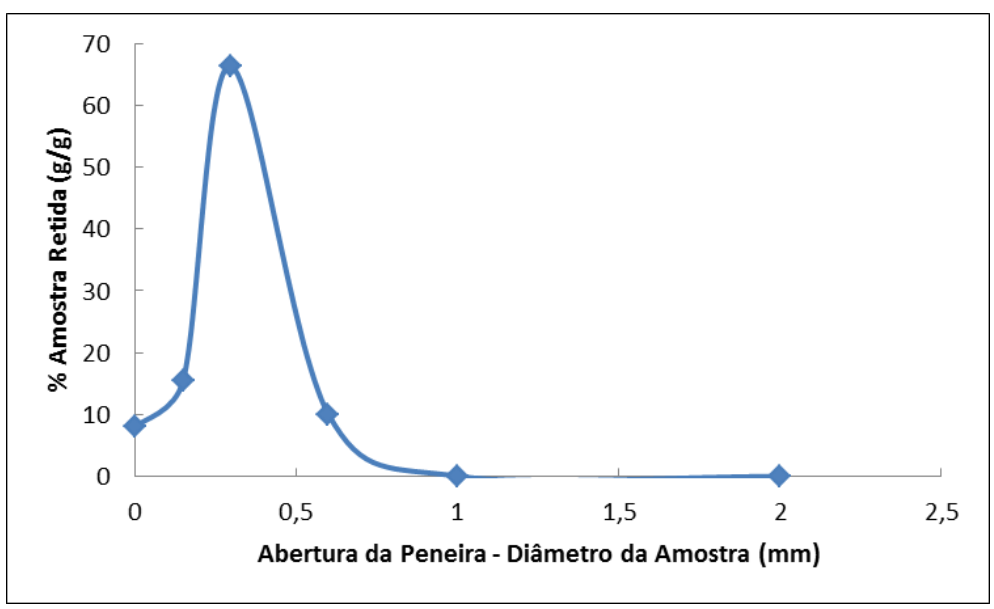

Pode-se observar por meio da Figura 1 que a palha de milho após o processo de moagem pelo moinho de facas, apresenta uma distribuição de tamanho de partículas entre 0 e $1 \mathrm{~mm}$, sendo que o tamanho médio das partículas foi de $0,28 \mathrm{~mm}$. Para a realização de reações de hidrólise, química ou enzimática, da biomassa, o conhecimento da distribuição de tamanho é de suma importância, visto que o tamanho da partícula está diretamente relacionado com a eficiência dos processos de pré-tratamento e hidrólise da biomassa.

\subsection{Teor de umidade e sólido totais}

O teor de umidade e sólidos totais da biomassa palha de milho, estufa e infravermelho, é apresentado na Tabela 1 .

Tabela 1 - Teor de umidade da palha de milho após a etapa de pré-secagem da biomassa utilizando duas metodologias de secagem, estufa e infravermelho.

\begin{tabular}{ccc}
\hline & \% Umidade & \% Sólidos \\
\hline Estufa & 5,24 & 94,76 \\
Infravermelho & 5,93 & 94,07 \\
\hline
\end{tabular}

Os valores encontrados para o teor de umidade são relativamente baixos em relação aos valores encontrados na literatura, uma vez que para o estudo em questão houve uma présecagem do material em estufa na etapa de preparação do material, a qual antecedeu a etapa de moagem. Contudo, se assemelham com os citados por Souza et al. (2005) que encontrou valores que variam de 7,4 a 8,8\% de umidade no bagaço de sorgo previamente seco.

\subsection{Teor de cinzas, extrativos e lignina insolúvel}


O teor de cinzas, extrativos e lignina insolúvel para a palha de milho foi de 4,01, 22,61 e $8,53 \%$, respectivamente.

De acordo com Silva (1997) a biomassa em estudo apresentou baixa concentração de inorgânicos (cinzas) em relação a outros materiais como a casca de arroz $12,6 \%$ e a palha de trigo 6,0\%. Entretanto, os teores de cinzas obtidos nesse trabalho são superiores aos citados por Souza et al. (2005), que apresenta valores entre 1,8 a $1,98 \%$ de cinzas no bagaço de sorgo. E diferem do teor de cinza do bagaço da cana-de-açúcar que varia entre 2 e $3 \%$ (Banerjee et al. 2002). No tocante ao aproveitamento de resíduos para a produção de bioetanol, buscam-se, principalmente, matérias-primas com baixo teor de cinzas, reduzindo assim o descarte de resíduos inorgânicos ao longo do processo.

Em relação aos extrativos, Salazar et al. (2005) relataram para a palha de milho $28,53 \%$ de extrativos, já Luana (2010) encontrou uma porcentagem de 5,85 para o mesmo material, 10,51 para a folha e 11,31 para o caule.

\section{REFERÊNCIAS}

BANERJEE, R.; PANDEY, Bio-industrial applications of sugarcane bagasse: a technological perspective. International Sugar Journal, Glamorgan, v.104, n.1328, 2002.

HAMES, B., RUIZ, R., SCARLATA, C., SLUITER, A., SLUITER, J., TEMPLETON, D. Preparation of Samples for Composition Analysis. Nat. Ren. Energy Lab., v. 1-12, 2005.

LUANA E. R. P. Produção e avaliação de briquetes de resíduos lignocelulósicos. Dissertação do Programa de Pós-Graduação em Ciência e Tecnologia da Madeira. Universidade Federal de Lavras. Lavras - MG. 2010, p. 83.

RABELO, S. C. Avaliação e otimização de pré-tratamentos e hidrólise enzimática do bagaço de cana-de-açúcar para a produção de etanol de segunda geração. Tese Doutorado em Engenharia Química. Universidade Estadual de Campinas - Unicamp, Faculdade de Engenharia Química, Programa de Pós-Graduação em Engenharia Química. Campinas SP. 2010.

SALAZAR, R. F. S.; SILVA, G. L. P.; SILVA, M. L. C. P. Estudo da composição da palha de milho para posterior utilização como suporte na preparação de compósitos. Faculdade de Engenharia Química de Lorena - FAENQUIL. Lorena - SP. 2005, p.7.

SLUITER, A., RUIZ, R., SCARLATA, C., SLUITER, J., TEMPLETON, D. Determination of total solids in biomass. Nat. Ren. Energy Lab., v. 1-6, 2005.

SOUZA, C.C et al. Produtividade Do Sorgo Granífero Cv. Sacarino E Qualidade De Produtos Formulados Isoladamente Ou Combinados Ao Caldo De Cana-DeAçúcar. Ciência e Tecnologia, v25. Campinas, 2005.

TAPPI- Technical Association oh the Pulp and Paper Industry. TAPPI test methods T 204 om-88: solvent extractives of wood and pulp. Atlanta: Tappi Technology Park, 1996. 